\title{
Predição de Estresse em Ovelhas Prenhas e Lactantes com o Uso de Redes Neurais Artificiais
}

\author{
Evaluation of Stress Prediction in Pregnant and Lactating Sheep Using Artificial Neural \\ Networks
}

\author{
Diogo Cesar Gomes da Silva
}

Universidade Anhanguera-Uniderp, Programa de Pós-Graduação Stricto Sensu em Meio Ambiente e Desenvolvimento Regional. MS, Brasil.

E-mail: diogocgsilva@hotmail.com

\begin{abstract}
Resumo
Os indicadores de bem-estar animal na agropecuária ganharam um grande aliado com o avanço da tecnologia da informação, que foi a utilização de sistemas inteligentes para a predição de respostas, e utilizados como ferramentas nas tomadas de decisão. Dentre os sistemas inteligentes destacam-se as redes neurais artificiais, devido à redução no custo de implantação, e que permite a inserção de novas técnicas para solução de problemas complexos, como a predição de dados não-lineares e padrões de comportamento. Com este trabalho objetivou-se construir uma rede neural capaz de predizer índices de estresse no período final de gestação e pós-parto de ovelhas Pantaneiras por meio das Redes Neurais Artificais do tipo Perceptron. Utilizou-se variáveis térmicas e fisiológicas de ovelhas gestantes, obtidas no Centro Tecnológico de Ovinos (CTO) da Universidade Anhanguera Uniderp, utilizando 30 matrizes alojadas em um piquete comum durante as fases de pré e pós gestação, onde foram classificados três indicadores de estresse em função da frequência respiratória (Leve, Moderado e Alto). Para tanto, foi implementada uma Rede Multilayer Perceptron com uma camada de entrada, uma oculta (com sete neurônios) e uma camada de saída, com função de ativação tangente hiperbólica e softmax. A temperatura ambiente do ar, a umidade relativa, e as temperaturas da pele, do corpo, da lã, da cabeça, a retal e a frequência respiratória foram consideradas variáveis de entrada. Como variável preditiva, foi considerada o estresse animal. Os resultados podem ser considerados satisfatórios, visto que a Rede apresentou erro de entropia cruzada de 2,337 e predições incorretas de $1,1 \%$ em predizer o nível de estresse térmico das ovelhas nas três classificações propostas a partir dos dados de entrada.
\end{abstract}

Palavras-chave: Centro Tecnológico de Ovino. Sistemas Inteligentes. Treinamento de Redes Neurais.

\begin{abstract}
The indicators of animal welfare in agriculture have gained a great ally with the advancement of information technology, which was the use of intelligent systems for the prediction of responses, and used as tools in decision making. Among the intelligent systems, artificial neural networks stand out, due to the reduction in the cost of implantation, which allows the insertion of new techniques for solving complex problems, such as the prediction of non-linear data and behavior patterns. This work aimed to build a neural network capable of predicting stress indices in the final period of pregnancy and postpartum of Pantaneira ewes by means of Perceptron Artificial Neural Networks. Thermic and physiological variables of pregnant ewes, obtained at the Centro Tecnológico de Ovinos (CTO) of Universidade Anhanguera Uniderp, were used, using 30 matrices housed in a common paddock during the pre and post pregnancy phases, where three stress indicators were classified in respiratory rate function (mild, moderate and high). To this end, a Perceptron Multilayer Network was implemented with an input layer, a hidden layer (with seven neurons) and an output layer, with a hyperbolic and softmax tangent activation function. Ambient air temperature, relative humidity, and skin, body, wool, head, rectal and respiratory rate temperatures were considered to be input variables. As a predictive variable, animal stress was considered. The results can be considered satisfactory, since the Network presented a cross entropy error of 2.337 and incorrect predictions of $1.1 \%$ in predicting the level of thermal stress of the sheep in the three classifications proposed from the input data.
\end{abstract}

Keywords: Centro Tecnológico de Ovinos. Intelligent Systems.Training of Neural Networks.

\section{Introdução}

Para a melhoria do cenário da carne ovina no Brasil, relativa à qualidade da carne ofertada ao consumidor, é necessário melhorar a estrutura da cadeia produtiva da ovinocultura, incluindo o bem-estar animal, com o acompanhamento técnico especializado do animal desde o nascimento até o abate.

Um dos fatores de maior impacto nos sistemas produtivos de animais são os fatores ambientais, em especial, o efeito direto do clima sobre os animais, que ocorre principalmente devido a influência da temperatura do ar, radiação solar e pela umidade relativa do ar, quando associada à temperatura (TITTO et al., 1998). Desse modo, a avaliação do ambiente e do microclima de cada região em que os animais são submetidos, bem como, o estudo das respostas fisiológicas e comportamentais são imprescindíveis para compreender os mecanismos adaptativos e índices de conforto e melhor performance produtiva.

Regiões com elevadas temperaturas, ou variações de temperatura ambiente com acréscimo de ganho calórico, produzem consequentes alterações no sistema termorregulatório e, portanto, estresse calórico. Alterações 
fisiológicas podem ser observadas nesses cenários, como o aumento na liberação de cortisol, alterando o metabolismo, o comportamento e o bem-estar animal (SILANIKOVE, 2000). Há, ainda, os relatos com os prejuízos em relação à ingestão e metabolização de alimentos, capazes de afetar negativamente o desempenho e o rendimento da função reprodutiva (BROOM; JHONSON, 2000).

As principais vantagens de utilização de Redes Neurais Artificiais na predição de índices de estresse são sua aplicação em tempo real e, a rápida resolução de problemas práticos, sem a necessidade de definição de lista de regras ou de modelos precisos, como acontece com modelos de regressões lineares múltiplas. As Redes Neurais Artificiais utilizam programas de instruções sequenciais, utilizando regras de aprendizagem obtida através de exemplos, que permitem adquirir poder de generalização suficiente para reconhecer padrões e predizer cenários.

Os modelos de Redes Neurais Artificiais têm potencial de aplicação na agropecuária em situações que requeiram classificação de padrões, identificação e associação de padrões, aproximação de funções e aprendizado em áreas em que é difícil criar modelos precisos da realidade e com frequentes mudanças de ambiente (HAYKIN, 2001).

A aplicabilidade das Redes Neurais Artificiais é crescente e a redução no custo de implantação é constante à medida que se popularizam ferramentas computacionais que permitem a inserção de novas técnicas para solução de problemas complexos, como a predição de dados não-lineares e padrões de comportamento. A entrada e saída de dados dos sistemas produtivos são preditas nas análises múltiplas e paralelas das redes (MURASE, 2000).

As Redes Neurais Artificiais são modelos de processamento serial ou distribuídos paralelamente, procurando alcançar bom desempenho via interconexão de elementos computacionais simples. Os modelos exploram simultaneamente muitas hipóteses utilizando regras de aprendizagem que permitem adquirir poder de generalização suficiente para reconhecer padrões e predizer cenários (HAYKIN, 2001; FREEMAN; SKAPURA, 2002). Os modelos de redes neurais têm potencial de aplicação na produção animal quando é necessário um banco de dados que permita a compreensão das relações entre o ambiente e a exploração agropecuária (FERNANDEZ et al., 2006). Desse modo, o objetivo deste estudo foi o predizer o estresse térmico na fase de gestação e maternidade na ovinocultura com o uso de Redes Neurais Artificiais, com base em variáveis térmicas ambientais e fisiológicas de ovelhas gestantes.

\section{Material e Métodos}

A presente pesquisa foi desenvolvida no Centro Tecnológico de Ovino (CTO) da Universidade Anhanguera -
Uniderp, localizada na Fazenda Três Barras, no município de Campo Grande, estado de Mato Grosso do Sul. O clima da região é caracterizado como mesotérmico $\mathrm{Cwa}$ (tropical de altitude), com temperatura do mês mais frio entre 15 e $25{ }^{\circ} \mathrm{C}$, inverno seco e temperatura do mês mais quente maior que 30 ${ }^{0} \mathrm{C}$, segundo classificação Köppen (PEREIRA et al., 2011).

As variáveis utilizadas neste estudo foram: temperatura ambiente $\left({ }^{0} \mathrm{C}\right)$, a umidade relativa do ar $(\%)$, as temperaturas do corpo $\left({ }^{\circ} \mathrm{C}\right)$, da cabeça $\left({ }^{\circ} \mathrm{C}\right)$, da pele $\left({ }^{\circ} \mathrm{C}\right)$, da lã $\left({ }^{\circ} \mathrm{C}\right)$, retal $\left({ }^{\circ} \mathrm{C}\right)$ e a frequência respiratória $(\mathrm{mpm})$.

Foram selecionadas trinta ovelhas pantaneiras, sendo estas acompanhadas desde o início da prenhez até o parto. As trinta ovelhas prenhas foram separadas em um piquete de 2 hectares com pastagem de Brachiaria decumbens, e acesso a suplementação alimentar e água.

A coleta de dados no Centro Tecnológico de Ovinos (CTO) ocorreu no período de dezembro de 2019 a abril de 2020, sendo as amostragens padronizadas em horários (período da manhã, com início às 07h:00min) em dias prédeterminados, com duas coletas semanais.

As variáveis climáticas foram obtidas por meio de estação meteorológica do Instituto Nacional de Meteorologia (INMET), utilizando-se o valor médio (período da manhã) de cada data de coleta. Para avaliar a temperatura retal, utilizou-se um termômetro clínico veterinário digital, marca Incoterm, tendo como especificações técnicas: dimensões 190x11x35mm, peso bruto 195g, peso líquido 55g, plástico, com escala de 32 a $44{ }^{\circ} \mathrm{C}$, mantido no reto do animal até que emissão do sinal sonoro indicasse a temperatura estabilizada. As temperaturas da pele, corpo, cabeça e lã foram avaliadas com auxílio de termômetro infravermelho digita, de marca Incoterm, com faixa de medição: $-50^{\circ} \mathrm{C}$ a $330^{\circ} \mathrm{C}$, resolução: $0,1{ }^{\circ} \mathrm{C}$, exatidão: $-50{ }^{\circ} \mathrm{C} \sim 0{ }^{\circ} \mathrm{C}: \pm 4{ }^{\circ} \mathrm{C} 0{ }^{\circ} \mathrm{C} \sim 330{ }^{\circ} \mathrm{C}: 2 \% \pm$ $2{ }^{\circ} \mathrm{C}$, sensor: temperatura infravermelho, resposta espectral: $8 \sim 14 \mu \mathrm{m}$, diodo laser: saída $<1 \mathrm{mV}, 630 \sim 670 \mathrm{~nm}$, classe 2, tempo de resposta: < 1s, alimentação: 1 bateria de $9 \mathrm{~V}$ e dimensões de 134 x 88.5 x $36 \mathrm{~mm}$, apontados para regiões pré-determinadas. A frequência respiratória foi avaliada pela contagem de movimentos do flanco e costado dos animais durante 15 segundos. Os animais foram avaliados somente uma vez, a cada dia de coleta.

A classificação do estresse das ovelhas foi realizada por meio da adaptação da metodologia de Terrill e Slee (1991), e a classificação para estresse térmico de Silanikove (2000), utilizando a resposta da frequência respiratória como indicador de: estresse baixo (40-60mpm), moderado (60$80 \mathrm{mpm})$ e alto (80-120 mpm).

Para aplicar a modelagem de RNA, foram utilizados os passos do algoritmo exposto na Figura 1. 
Figura 1 - Algoritmo de aplicação da técnica RNA para a predição de estresse térmico de ovelhas pantaneiras nas fases de gestação e maternidade.

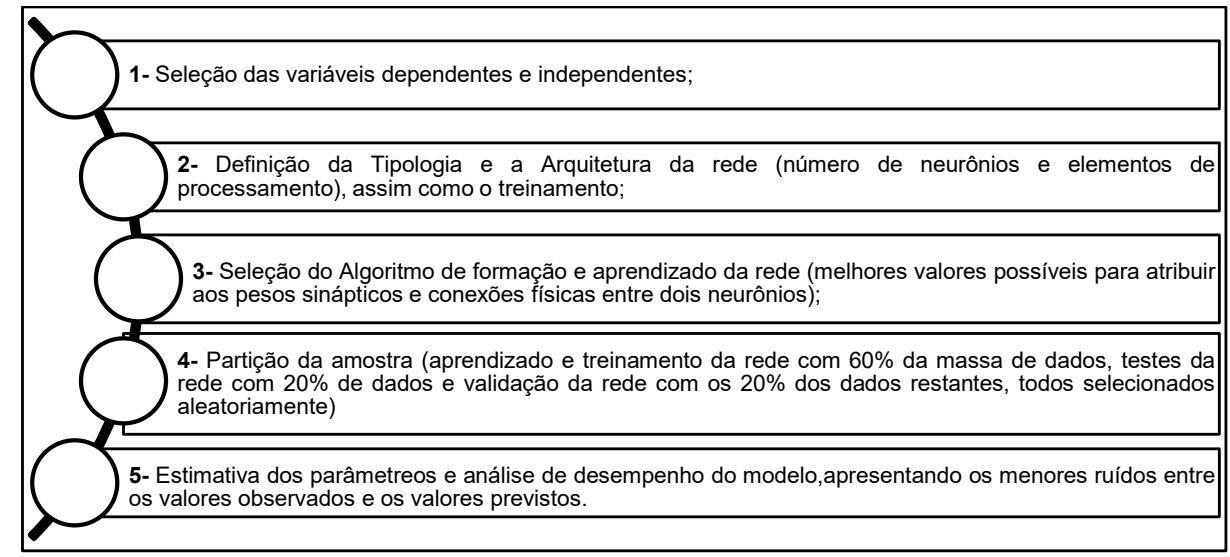

Fonte: Dados da pesquisa.

Para a aplicação do algoritmo da Figura 1 foi utilizado o software IBM-SPSS na seguinte configuração: RNA do tipo multilayer perceptron; uma camada oculta intermediária com $n$ neurônios e função de ativação tangente hiperbólica; algoritmo de aprendizagem backpropagation; redimensionamento de todas as variáveis (entrada e saída normalizadas) para minimizar o coeficiente de variação (decorrente das diferentes unidades físicas utilizadas); e a camada de saída, com função identidade como ativação. A saída do software fornece os valores observados e previstos, com o ajuste e os erros dados pelo erro de entropia cruzada e predições incorretas.

A classificação do estresse térmico das ovelhas foi realizada por meio de entropia cruzada, que pode ser usada como uma medida de erro quando as saídas de uma rede podem ser pensadas como representando hipóteses independentes e as ativações podem ser entendidas como representando a probabilidade (ou a confiança) que cada uma das hipóteses pode ser verdadeira. Nesse caso, o vetor de saída representou uma distribuição de probabilidade, e a medida de erro (entropia cruzada) indica a distância entre o que a rede acredita que essa distribuição deve ser e o que realmente deveria ser, conforme equação (1).

$$
H(p, q)=-\sum_{x} p(x) \log (q(x))
$$

Onde H (p, q) representa a entropia em termos probabilístico de eventos (p e q) e x representa o vetor de variáveis de entrada.

Conforme discutido por Barber, Sollich e Saad (2012), as funções de ativação introduzem um componente não linear nas redes neurais, isto é importante para que a rede possa aprender as relações lineares entre as variáveis dependentes e independentes. Para nossa adequada modelagem e diante do conjunto de dados utilizados, a função tangente hiperbólica ( $\tanh$ ) foi utilizada na camada de entrada diante de seu formato sigmoide característico, variando de -1 a 1 , se aproximando mais da função identidade. A equação da tanh (x) pode ser resumida na equação (2).

$$
\tanh (x)=\frac{\operatorname{senh}(x)}{\cosh (x)}=\frac{e^{x}-e^{-x}}{e^{x}+e^{-x}}
$$

Onde $\operatorname{senh}(x)$ é o seno hiperbólico de $x, \cosh (x)$ é cosseno hiperbólico de $\mathrm{x}, \mathrm{e}^{\mathrm{x}}$ e $\mathrm{e}^{-\mathrm{x}}$ são funções exponenciais de $\mathrm{x}$ no domínio da função.

Já, a função softmax, segundo Barber, Sollich e Saad (2012), que também apresentam um caráter sigmoidal, mas ao contrário de outras funções exponenciais, essa é mais indicada quando se está diante de um conjunto de dados de classificação. Tendo em vista que no presente estudo utilizouse três classificações de estresse (leve, moderado e elevado), a função softmax foi a função utilizada, pois, é mais adequada quando existem mais de duas classes de classificação. Essa função transforma as saídas, para cada classe, em valores entre 0 e 1, dando a probabilidade de a entrada estar em uma determinada classe. Sua equação é definida por (3).

$$
\emptyset_{i}=\frac{e^{z_{i}}}{\sum_{j \in \text { grupo }} e^{z_{j}}}
$$

Onde i representa o índice do neurônio de saída e j representa o índice de todos os neurônios de um nível. A variável $z$ designa o vetor de neurônios de saída.

\section{Resultados e Discussão}

As estatísticas descritivas dos dados climáticos e fisiológicos das trinta ovelhas pantaneiras, referentes ao período de 12/2019 a 04/2020, estão no Quadro 1.

Quadro 1 - Estatísticas Descritivas das variáveis climáticas e fisiológicas de ovelhas pantaneiras do CTO, no período de $12 / 2019$ a $04 / 2020$

\begin{tabular}{|l|c|c|c|c|c|}
\hline \multicolumn{1}{|c|}{ Variáveis } & Média & $\begin{array}{c}\text { Desvio } \\
\text { Padrão }\end{array}$ & $\begin{array}{c}\text { CV } \\
(\%)\end{array}$ & Mínimo & Máximo \\
\hline $\begin{array}{l}\text { Temperatura } \\
\text { retal }\end{array}$ & 38,91 & 0,83 & 2,13 & 28,76 & 41,20 \\
\hline $\begin{array}{l}\text { Temperatura } \\
\text { do corpo }\end{array}$ & 37,41 & 1,44 & 3,85 & 32,11 & 39,56 \\
\hline
\end{tabular}


Continuação..

\begin{tabular}{|l|c|c|c|c|c|}
\hline \multicolumn{1}{|c|}{ Variáveis } & Média & $\begin{array}{c}\text { Desvio } \\
\text { Padrão }\end{array}$ & $\begin{array}{c}\mathbf{C V} \\
\mathbf{( \% )}\end{array}$ & Mínimo & Máximo \\
\hline $\begin{array}{l}\text { Temperatura } \\
\text { da cabeça }\end{array}$ & 36,55 & 1,51 & 4,13 & 23,70 & 42,00 \\
\hline $\begin{array}{l}\text { Temperatura } \\
\text { da lã }\end{array}$ & 33,69 & 3,45 & 10,24 & 22,00 & 40,00 \\
\hline $\begin{array}{l}\text { Temperatura } \\
\text { da pele }\end{array}$ & 36,17 & 2,85 & 7,88 & 26,00 & 71,70 \\
\hline $\begin{array}{l}\text { Frequência } \\
\text { respiratória }\end{array}$ & 71,31 & 13,12 & 18,40 & 24,00 & 120,00 \\
\hline $\begin{array}{l}\text { Temperatura } \\
\text { do ar }\end{array}$ & 26,47 & 1,77 & 6,69 & 22,32 & 29,55 \\
\hline $\begin{array}{l}\text { Umidade } \\
\text { relativa do ar }\end{array}$ & 70,08 & 8,33 & 11,89 & 54,58 & 84,00 \\
\hline
\end{tabular}

Legenda: $\mathrm{CV}$ : Coeficiente de variação; Temperatura $\left({ }^{\circ} \mathrm{C}\right)$; Umidade relativa do ar (\%); Frequência respiratória (mpm).

Fonte: Dados da pesquisa.

Os resultados de temperatura do ar e umidade relativa, do presente estudo, encontram-se dentro da zona termoneutra, que segundo Baêta e Souza (1997) se situam entre 20 e 30 ${ }^{\circ} \mathrm{C}$ e umidade relativa do ar entre $60-70 \%$. valores médios de temperatura e umidade, presentes no Quadro 1, apresentam-se dentro da zona termoneutra $\left(26,47{ }^{\circ} \mathrm{C} \pm 1,77\right.$ e Umidade de $70,08 \pm 8,33 \%$ ).

Em relação aos parâmetros fisiológicos, a temperatura retal média também é considerada normal (Quadro 1). De acordo com os resultados de Silva Sobrinho (2001), a temperatura retal normal de ovinos adultos situa-se entre $38,5^{\circ} \mathrm{C}$ e $40{ }^{\circ} \mathrm{C}$. Para a frequência respiratória, a média de 71,31 mpm (Quadro 1) representa valores acima do fisiológico que segundo Santos et al. (2001) é considerado fisiológico em FR < 40mpm, em condições de termoneutralidade. Tal resultado presente no Quadro 1 pode refletir tanto a condição gestacional das fêmeas (maior produção de calor endógeno), como a respostas a agentes estressores ambientais diversos (SANTOS et al., 2006; HOOPER et al., 2018).

Distúrbios no ambiente dos animais podem alterar a variação da temperatura corporal, por meio de uma maior ativação do córtex adrenal e consequentemente aumento da temperatura corporal. As variações na concentração dos hormônios da tireoide e das adrenais é de extrema importância quando se relaciona estresse térmico e metabolismo (DICKSON, 1996), o que inclui condições estressoras diversas (BROOM; JOHNSON, 2000).

Observando a coluna dos coeficientes de variação CV (\%) do Quadro 1, nota-se valores abaixo de 15\%, demonstrando uma certa homogeneidade dos dados coletados. Destaca-se, o coeficiente de variação da frequência respiratória, que atingiu $18,40 \%$, um valor alto, destoando dos demais. Em uma análise mais minuciosa, percebe-se que a amplitude total das frequências respiratórias é muito grande, de $96 \mathrm{mpm}$, com o valor mínimo de 24 e valor máximo de $120 \mathrm{mpm}$.

A modelagem da RNA MLP mais adequada para o modelo preditivo foi a de uma rede com uma camada de entrada, com oito neurônios, correspondentes às variáveis preditoras: temperatura do ar (Temp_Ar), temperatura retal (Temp_ Retal), temperatura do corpo (Temp_Corpo), temperatura da cabeça (Temp_Cabeça), umidade relativa do ar (Umidade), frequência respiratória (FR), temperatura da pele (Temp_Pele) e temperatura da lã (Tem_Lã), uma camada oculta (com sete neurônios), e função de ativação do tipo tangente hiperbólica e uma camada de saída, correspondentes às variáveis do estresse térmico: leve (Estresse_1), moderado (Estresse_2) e elevado (Estresse_3), com função de ativação do tipo softmax. O layout da RNA mostrado na Figura 2, apresenta as ponderações sinápticas e funções de ativação.

Figura 2 - Layout da RNA e ponderadores de sinapse para a predição de estresse térmico de ovelhas pantaneiras nas fases de gestação e maternidade, em abril de 2020

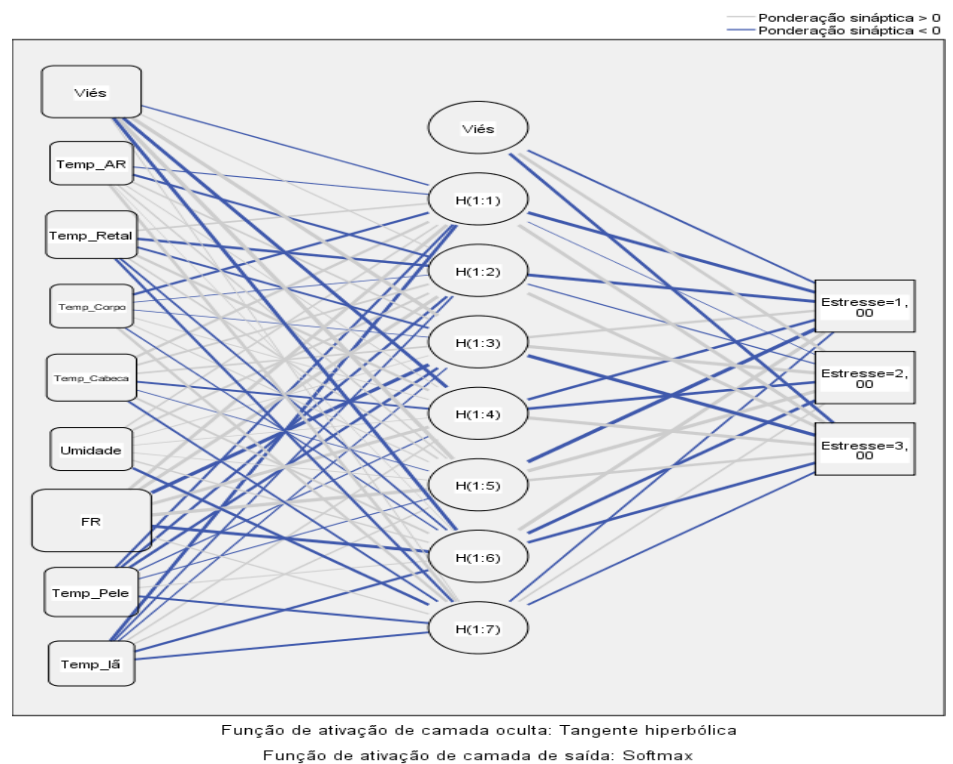

Fonte: Adaptado de IBM_SPSS (2020) 
A arquitetura da RNA da Figura 2 é chamada arquitetura feedforward porque as conexões de rede fluem unidimensionalmente da camada de entrada para a camada de saída sem loops de feedback (KOVÁCS, 2006; BRAGA; CARVALHO; LUDEMIR, 2014). A camada de entrada contém os preditores, a camada oculta contém nós (ou unidades) não observáveis. $\mathrm{O}$ valor de cada unidade oculta é uma função dos preditores; a forma exata da função depende, por um lado, do tipo de rede e, por outro lado, das especificações controláveis pelo usuário (SILVA; SPATTI; FLAUZINO, 2010). A camada de saída contém as respostas estresse térmico: leve, estresse moderado e elevado.

As linhas representam as ponderações sinápticas, ou seja, os ponderadores utilizados pelas funções de ativação das camadas ocultas e saída. Valores maiores que 0 são representados por linhas mais proeminentes, o que indicam uma maior ponderação ou "grau de importância" da variável no modelo (KOVÁCS, 2006; BRAGA; CARVALHO; LUDEMIR, 2014).

Em relação ao desempenho de predição da RNA, o Quadro 2, apresenta o resultado da variável dependente classe de estresse em relação ao percentual correto após treinamento.

Quadro 2 - Porcentagem global correta da predição da variável estresse das amostras de treinamento e teste da RNA para a predição de estresse térmico de ovelhas pantaneiras nas fases de gestação e maternidade, em abril de 2020

\begin{tabular}{|c|c|c|c|c|c|}
\hline \multirow[b]{2}{*}{ Amostra } & \multirow[b]{2}{*}{ Observado } & \multicolumn{4}{|c|}{ Predito em mpm } \\
\hline & & $\begin{array}{c}\text { Estresse baixo } \\
(40-60)\end{array}$ & $\begin{array}{c}\text { Estresse médio } \\
(60-80)\end{array}$ & $\begin{array}{c}\text { Estresse alto (80- } \\
120)\end{array}$ & $\begin{array}{c}(\%) \\
\text { Correta }\end{array}$ \\
\hline \multirow{4}{*}{ Treinamento } & Estresse baixo (40-60) & 43 & 0 & 0 & 100 \\
\hline & Estresse médio (60-80) & 0 & 142 & 0 & 100 \\
\hline & Estresse alto (80-120) & 0 & 0 & 30 & 100 \\
\hline & (\%) Acerto Global & $20,0 \%$ & $66,0 \%$ & $14,0 \%$ & 100 \\
\hline \multirow{4}{*}{ Testes } & Estresse baixo (40-60) & 18 & 0 & 0 & 100 \\
\hline & Estresse médio (60-80) & 1 & 62 & 0 & 98,4 \\
\hline & Estresse alto (80-120) & 0 & 0 & 10 & 100 \\
\hline & ( \% ) Acerto Global & $20,9 \%$ & $68,1 \%$ & $11,0 \%$ & 98,9 \\
\hline
\end{tabular}

Fonte: Dados da pesquisa.

A taxa de erro global foi de 1,1\% (Quadro 2) nos Testes da rede, um resultado satisfatório para a predição de classes de estresse em ovelhas pantaneiras a partir das variáveis climáticas e fisiológicas utilizadas. $\mathrm{Na}$ construção da arquitetura da rede, utilizou-se de $30 \%$ do conjunto de dados para treinamento, o que significa durante o treinamento, o algoritmo da rede opera em uma sequência passos. Primeiro, identifica um padrão e o apresenta à camada de entrada da rede. Tal resposta resultante "passa" através da rede, camada por camada, até que a resposta seja produzida pela camada de saída. Em um segundo momento, a saída obtida é comparada à saída desejada (variável dependente). Se o valor for distinto, então o erro é calculado, e este erro é propagado a partir da camada de saída até a camada de entrada, e os ponderadores das camadas internas vão sendo modificados conforme o erro é retropropagado. Desta forma, quando se avalia um erro global na fase de teste de $1,1 \%$, admite-se uma satisfatória predição diante de dados biológicos, demonstrando a eficiência do algoritmo da rede para identificar o padrão do conjunto de dados.

A importância de cada variável independe para a predição da classificação de estresse pode ser observada n o Quadro 3.
Quadro 3 - Importância e importância normalizada das variáveis independentes da RNA para a predição de estresse térmico de ovelhas pantaneiras nas fases de gestação e maternidade

\begin{tabular}{|l|c|c|}
\hline Variável & Importância & $\begin{array}{c}\text { Importância } \\
\text { normalizada (\%) }\end{array}$ \\
\hline Temperatura do ar & 0,036 & 8,3 \\
\hline Temperatura retal & 0,125 & 28,7 \\
\hline Temperatura do corpo & 0,036 & 8,3 \\
\hline Temperatura da cabeça & 0,113 & 25,9 \\
\hline Umidade relativa do ar & 0,027 & 6,1 \\
\hline Frequência respiratória & 0,437 & 100,0 \\
\hline Temperatura da pele & 0,156 & 35,7 \\
\hline Temperatura da lã & 0,069 & 15,7 \\
\hline
\end{tabular}

Legenda: Temp. (Temperatura, ${ }^{\circ} \mathrm{C}$ ), Umidade (Umidade Relativa do $\mathrm{Ar}$, \%); FR (Frequência Respiratória, movimento por minuto - mpm).

Fonte: Dados da pesquisa.

Desta forma, pode-se observar na Quadro 3 que a utilização dos indicadores climáticos locais e das variáveis fisiológicas dos animais foram eficazes na construção de um modelo preditivo de estresse térmico, sendo a frequência respiratória, a temperatura retal e a temperatura da pele e cabeça, as mais relevantes para o modelo.

\section{Conclusão}

A modelagem da RNA para predição de classes de estresse térmico em ovelhas pantaneiras foi adequada, com 
erros de predição de $1,1 \%$ a partir de variáveis climáticas (temperatura do ar e umidade relativa do ar) e parâmetros fisiológicos (temperaturas do corpo, pele, cabeça, lã e retal) e frequência respiratória. A utilização da RNA permitiu construir um modelo com capacidade de predição de níveis de estresse calórico, identificando as variáveis com potenciais de causarem os maiores estresses em ovelhas pantaneiras nas fases de gestação e maternidade.

\section{Agradecimentos}

Agradecimentos ao Conselho Nacional de Desenvolvimento Científico e Tecnológico (CNPq) e à Fundação Nacional de Desenvolvimento do Ensino Superior (FUNADESP), pelos apoios financeiros das bolsas de iniciação científica.

\section{Referências}

BAÊTA, F.C.; SOUZA, C.F. Ambiência em edificações rurais: conforto animal. Viçosa: UFV, 1997.

BARBER, D.; SOLLICH, P.; SAAD, D. Finite Size Effects in on-line learning of multi-layer Neural Network. In: ELLACOTT, S.W.; MASON, J.C.; ANDERSON, I.J. mathematics of neural networks: models, algorithms and applications. Manchester: Springer Science, 2012. p.84-88.

BRAGA, A.P.; CARVALHO, A.P.L.F.; LUDERMIR, T.B. Redes neurais artificiais: teoria e aplicações. Rio de Janeiro: LTC, 2014.

BROOM, D.M.; JOHNSON, K.G. Stress and animal welfare. Dordrecht: Kluver Academic Publishers, 2000.

DICKSON, W.M. Endocrinologia, reprodução e lactação. Glândulas endócrinas. In: SWENSON, M.J.; REECE, W.O. Dukes fisiologia dos animais domésticos. Rio de Janeiro: Guanabara, 1996. p.572-614.

FERNANDEZ, C. Neural networks for animal science applications: two case studies. Expert Syst. With Applic.. v.31, n.2, p.444-450, 2006. doi: 10.1016/j.eswa.2005.09.086
FREEMAN, J.A.; SKAPURA, D.M. Neural networks: algorithms, applications, and programming techniques. California: CNS, 1991.

HAYKIN, S. Redes neurais princípios e prática. Porto Alegre: Artmed, 2001.

HOOPER, H.B. et al. Bem-estar durante o período gestacional de ovelhas: uma breve revisão. Rev. Acad. Ciênc. Anim., v.16, p.110, 2018. doi: 10.7213/1981-4178.2018.161104

KOVÁCS, Z. L. Redes neurais artificiais: fundamentos e aplicações. São Paulo: Livraria da Física, 2006.

MURASE, H. Editorial: artificial intelligence in agriculture. Comp. Electr. Agric., v.29, p.1-2, 2000.

PEREIRA, A.A. et al. Análise da distribuição espacial de áreas queimadas através da função K de Ripley. Scie. Forestalis, v.41. n.100, p.445-455, 2013.

SANTOS, J.R.S. et al. Respostas fisiológicas e gradientes térmicos de ovinos das raças Santa Inês, Morada Nova e de seus cruzamentos com a raça Dorper às condições do semi-árido nordestino. Ciênc. Agrotecnol., v.30, p.995-1001, 2006. doi: 10.1590/S1413-70542006000500025

SANTOS, M.M. et al. Comportamento de ovinos da raça Santa Inês, de diferentes pelagens, em pastejo. Acta Scie. Animal Scie., v.33, p.287-294, 2011. doi: 10.4025/actascianimsci.v33i3.9974

SILANIKOVE, N. Effects of heat stress on the welfare of extensively managed domestic ruminants, Levistok Producion. Sci., v.67, p.1-18, 2000. doi: 10.1016/S0301-6226(00)00162-7

SILVA, I.N.; SPATTI, D.H.; FLAUZINO, R.A. Redes neurais artificiais: para engenharia e ciências aplicadas. São Paulo: Artliber, 2010.

TERRILL, C.E.; SLEE, J. Breed differences in adaptation of sheep, In: MAIJALA, K. Genetic resources of pigs, sheep and goat, Amsterdam: Elsevier, 1991. p.195-233.

TITTO, E.A.L. et al. Termorregulação em ovinos: estudo de temperatura retal, frequência respiratória e ingestão de água. Rev. Port. Zootec., v.5, n.1, p.56-65, 1998. 